Revista Iberoamericana, Vol. LXXVIII, Núms. 238-239, Enero-Junio 2012, 179-192

\title{
CIENCIA-FICCIÓN Y CONFIGURACIÓN IDENTITARIA EN GEL AZUL: EN TORNO A UNA MEXICANIDAD FUTURA
}

\author{
POR \\ HÉCTOR FERnÁNDEZ L'Hoeste \\ Georgia State University
}

Una de las mayores virtudes de la ciencia-ficción es la de fungir de laboratorio identitario, pues nos permite imaginarnos mundos futuros, en los que proyectos de nación maduran o desaparecen, con fortuitas expansiones del campo cultural y circunstancias impredecibles matizadoras de nuevas diferencias.

En el 2007, el historietista mexicano Bernardo Fernández (1972, ninguna relación con el autor de este artículo), también conocido como Bef, conquista el premio Ignotus con su novela Gel azul. Gracias a ello, la obra logra publicarse en España a través de Ediciones Parnaso, con una portada diagramada por el también historietista mexicano Sebastián Carrillo, mejor conocido como Bachan y frecuente compañero de andanzas de Bef. Varios años más tarde, Suma de Letras, una subsidiaria de Santillana, lanza la novela en México, dándola a conocer como novedad de la ciencia-ficción azteca. En ella, Bef narra la historia de un México futuro en el que la máxima expresión de estatus consiste en vivir sumergido en tanques de gel azul, con la consiguiente optimización de una realidad virtual. En un giro macabro, la trama parte del hallazgo de un bebé flotando en el tanque de Gloria Cubil, hija del hombre más adinerado del país. A raíz de este incidente, el investigador protagonista, un ex hacker llamado Crajales, descubrirá una serie de intrigas delatoras de un lucrativo tráfico de órganos. En este sentido, Bef postula una distopía, una realidad futura en la que las diferencias sociales rebasan el ámbito físico y en la que lo físico, suplido por lo virtual, deviene en materia mercantil. De esta manera, Bernardo Fernández nos advierte acerca de las contradictorias posibilidades de un sueño tecnológico convertido en pesadilla, en el que, una vez violentadas las barreras de lo espacio-temporal, gracias a avances en materia de comunicación y el aceleramiento de una disposición global, se plantea una regresión hacia dimensiones más primigenias como la comercialización del cuerpo.

Mi crítica del texto nace de esta lectura. En el marco de Gel azul, Japón suplanta a EE.UU. como paradigma preferente de desarrollo. Según este delineamiento, pese a los logros tecnológicos, la mexicanidad ofrecida por Bef se destaca por un afianzamiento aislacionista y la correspondiente reafirmación identitaria -a la manera nipona-, su 
incapacidad de postular una relación utilitaria con un desarrollo posibilitador de una mejora generalizada del bienestar social y, en última instancia, el prolongamiento de esquemas de la sociedad nacional que dan al traste con la tarea de imaginarse un México más justo e igualitario. Dentro de este contexto, como formulación distópica, Gel azul se fundamenta en una nueva alteridad, mas sólo logra replegarse hacia las aristas más pronunciadas de la mexicanidad contemporánea.

En primera instancia, con el fin de establecer de manera clara los términos de la diagramación de un espacio narrativo en Gel azul, vale la pena examinar el hipotético trazado de Ciudad de México en el tiempo futuro de la novela. El esquema es particularmente consonante dado que patentiza cómo se organizará el espacio físico para autenticar una visión aún más estratificada de la participación ciudadana. Según la narración, la ciudad se encuentra organizada en una serie de círculos concéntricos (29), de cierta manera repitiendo e intensificando el diseño actual. En el corazón de la urbe, en la Vieja Ciudad, área correspondiente al actual Centro Histórico y zonas colindantes, se ubican los focos corporativos, agentes de un nuevo orden económico, y las casas y departamentos de la clase acomodada, con áreas muy superiores a las de las residencias en los círculos siguientes. En otras palabras, la tendencia demográfica reafirma el que, a medida que se avance hacia los límites del perímetro urbano, aumente la densidad habitacional y disminuya la calidad de vida. Entre más alejados estén del centro, más apretujados estarán los habitantes, cosa que no se da hoy en día si se toma en cuenta, por citar algún ejemplo, el caso de Santa Fe o Coyoacán. Sin embargo, al llegar a los extramuros de la ciudad el paisaje se pierde en un llano despoblado, de manera que la elevada densidad se eclipsa de forma súbita.

Según la descripción contenida en la historia, en la Zona Dos, el grueso anillo que rodea el centro de manera inmediata, viven los del medio, quienes, más allá de la supuesta conveniencia de una proximidad interior, han optado por marcar cierta distancia con las postrimerías de la ciudad. Su nivel de vida no es envidiable. En la adjunta Zona Tres viven hacinados los burócratas y obreros posibilitadores del bienestar de la élite, cual hormigas obreras. Habitan estructuras semejantes a colmenas, con millones de capullos de acrílico y aluminio, de manera un tanto similar a ciertas residencias modulares que alcanzan a verse hoy en día en la tierra del sol naciente: los módulos para pasajeros abandonados por el metro en Tokio, por citar otro ejemplo. Más allá, están los basureros, los tiraderos, improvisados remedos de rellenos sanitarios en los que habitan quienes han sido rechazados por la sociedad. Y aún más allá, según hemos mencionado, sólo queda el desierto, testimonio mudo del suelo lacustre de antaño. Ahora bien, este esquema urbanista, tan rígido y estratificado, tan empecinado en sustentar un orden social pleno de desigualdad, encaja a la perfección con las premisas fundamentales del cyberpunk, habituado a tramas con elevado despliegue de tecnología mas un bajísimo nivel de vida, a la manera de Blade Runner (1982). Con el despliegue de este arreglo espacial desde

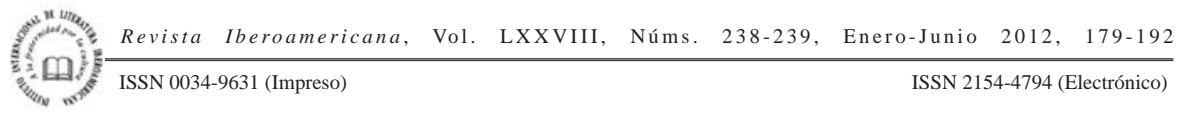


tempranas páginas de la narración, Fernández le aclara su situación -literaria, física, en términos del relato- a los lectores.

Asimismo, otra faceta destacable de este énfasis en explicar cómo ha ido evolucionando la urbe es el interés por el grafismo, por la posibilidad de que los lectores puedan imaginarse de manera concreta y explícita, muy visual -y en esto tiene mucho que ver el hecho de que Bernardo Fernández también se gane el pan como historietista-, cómo ha de ser la vida en una ciudad de este estilo. Es a partir del entendimiento de este arreglo espacial que se nos permite, como lectores, adentrarnos en una versión de la futura realidad mexicana en la que lo real ha sido suplido por lo virtual. Por tanto, la acuciosa descripción del entorno urbano no es sino una forma más de justificar que, a partir de una materialidad desesperante y hostil, se busque un goce imaginario, proveedor de circunstancias más placenteras. Para resumir: imaginar una realidad horrenda facilita el entendimiento de un afán de escapismos. En términos básicos, la premisa de la historia es que el ámbito material, tan problemático para el entendimiento de la mexicanidad, dada su materialización de una rampante desigualdad social y, por consiguiente, su continua aseveración de las deficiencias del modelo económico nacional, es suplantado por mundos virtuales en los que resulta factible implementar una cierta equidad general, independiente de la inicial exigencia de solvencia económica para acceder a estos mundos. En pocas palabras, según Bef, en el México del futuro el afán de escapismo triunfará, sea como sea.

Para Crajales, un ex-pirata informático metido a detective, la incomodidad del mundo material, tan desigual -y para ser francos, tan grotesco-, llega por cortesía de un pasado turbio en el que el personaje perdió la posibilidad de deambular por ámbitos virtuales. Los pasajes de la obra dedicados a la descripción de la movilización del protagonista a lo largo de la ciudad, con niños mendigos que agreden a los pasajeros de taxis a punta de picotazos de jeringa (50) o bandas de adolescentes que, en medio del estupor de la drogadicción, acosan al transeúnte (66), denotan un ambiente contrario, empecinado en cuestionar la existencia de seres humanos en su entorno. Incluso el despacho del protagonista, de apenas dieciséis metros cuadrados, con paredes descascaradas y pisos de linóleo, parece querer ahuyentar a quien lo habita. Y para colmo, para ir de casa al trabajo, y viceversa, hace falta un trayecto de cuatro horas en metro, tomar el electrobús del vecindario y, en caso de que el ascensor no funcione, subir diecisiete pisos a pie (30). (Crajales vive en la Zona Dos, así que ni hablar de quienes vivan más allá, si es que a esas alturas les llega el metro.) En síntesis, el mundo de Crajales se encuentra matizado, desde un comienzo, por su condena a vivir (y sufrir) semejante desbarajuste.

Precisamente, de no haber sido por el desliz de otrora, Crajales hubiera sido capaz de compartir a seguido la realidad virtual de los más afortunados. Al fin y al cabo, en el cuello del personaje alcanzan a verse los extremos de una interfaz neural que, hará cosa de veinticinco años, fungía de tecnología de punta (27). (En otras palabras, muchos años

\footnotetext{
Revista Iberoamericana, Vol. LXXVIII, Núms. 238-239, Enero-Junio 2012, 179-192 
antes de que se inventaran las interfaces multisensoriales, con las cuales se hizo factible, según el mundo futuro de Gel azul, saborear y olfatear los enésimos reinos imaginarios de la Red.) Hace muchos años, según nos deja saber el relato, cuando Crajales tenía apenas catorce años, era un avezado cibernauta, acostumbrado a violentar medidas de seguridad y saquear las cuentas bancarias de otros con el fin de rellenar sus bolsillos e incluso asignarse un certificado de bachillerato completo tras ser expulsado de la secundaria (79). Su compañero de travesuras, el gordo Salgado, era un ser acomplejado, acostumbrado a vivir bajo la sombra de su amigo, a quien idolatraba consumido por la envidia. La naturaleza malsana de semejante dependencia se mantiene hasta que Salgado opta por traicionar a su ídolo (spoiler alert: esta circunstancia sólo es conocida por los lectores al final de la obra). Luego de una de las consabidas sesiones de piratería, Salgado deja la tarjeta de crédito de Crajales en un cajero automático de la Zona Rosa, adonde han ido a conectarse para pasar desapercibidos - es decir, para no ser rastreados hasta sus respectivas residencias-, de manera que, tras el conocimiento del desfalco, su identidad sea fácil de concretar. A raíz de este entuerto Crajales es capturado y su interfaz sufre un cortocircuito, con lo que queda en coma por ocho meses y doce días e inhabilitado de por vida para sumirse de nuevo en mundos virtuales. A partir de este instante, será Salgado quien cosechará triunfos, ascenderá en la escala social y terminará siendo reportero cibernético, agenciándose el privilegio de monitorear la actividad en los universos virtuales del gel azul para la prensa capitalina. Crajales, ajeno a la traición de su compinche, se hundirá en un mar de mediocridad y terminará operando como investigador de tercera, acostumbrándose a circular por los inframundos de la capital azteca. Acabará casándose de manera tardía con una arribista ex secretaria del ministerio público quien, al cabo de varios años, comenzará a serle infiel con su jefe de turno. De ahí que una de las mayores motivaciones de la trama sea el anhelo del detective por lograr acceso a ese mundo prohibido, el espacio de lo virtual, en busca de un poco de sosiego para su atribulada existencia. Ante el desagradable devenir de su vida material, el detective adivina en la muerte del nieto del archibillonario Arceo Cubil-Iñaki Beltrán, el abogado que lo contrata a nombre del acaudalado empresario, le suelta el doble de lo que normalmente cobra sin chistar un instante- una latente oportunidad para hacerse merecedor de una nueva interfaz.

Ahora bien, cabe preguntarse, si en un mundo en el que los seres más privilegiados, -a fin de cuentas, la clase pudiente de un país, los únicos con la capacidad de costear hábitos tan prohibitivos- buscan a toda costa la posibilidad de sumirse en un mundo imaginario, ¿qué destino le espera al imaginario nacional? Si quienes más cuentan a la hora de pensar el país -nos guste o no, a raíz de la acumulación de capital económico, que no simbólico- están sumidos en un sueño colectivo, más preocupados por dar de baja y aniquilar a la madre de insectos robots aglutinados en una nave espacial que por darle un rumbo coherente al estado y cumplir con su deber cívico, ¿quién demonios

\footnotetext{
(3) Revista Iberoamericana, Vol. LXXVIII, Núms. 238-239, Enero-Junio 2012, 179-192 ISSN 0034-9631 (Impreso) 
está al mando? Las masas, ciertamente más preocupadas en ganarse el pan diario que en elucubrar acerca de la integridad nacional, no habrán de quedarse calladas, pero su incidencia será de menor estatura. Independiente de la respuesta, en el contexto de la trama de $\mathrm{Gel}$, en el que las máquinas facilitadoras de experiencias virtuales desempeñan un papel preponderante, lo que resulta evidente es la menor participación de las poblaciones desfavorecidas en la definición de un imaginario casi literal. En este sentido, el pensamiento identitario se transforma en operación de segundo orden, pues los mexicanos acomodados acostumbran internarse, según nos permiten teorizar los repetidos viajes de Gloria Cubil por espacios virtuales -convertida en medusa e intentando ocultar su condición de género de manera recelosa; a veces circulando desnuda por entre bares, en busca de un amor verdadero y algo de serenidad tras haber soñado dar a luz (cosa que juzga insensata, dada su condición fisiológica)-, en mundos imaginarios por lapsos extendidos de tiempo, abandonando de lleno sus funciones dentro del marco más amplio de la sociedad nacional. La idea no es conectarse a una máquina para ser más eficiente y poder manejar las cosas de mejor manera, como afirma el ingeniero Montanaro, encargado del mantenimiento de las máquinas, cuando Crajales lo interroga acerca del funcionamiento de las mismas. La idea es conectarse a la máquina para dejarse perder en un cúmulo de experiencias que ya no son factibles en el mundo real, olvidándose del diario quehacer. Según el autor, es por ello que el país azteca deviene en fructuoso mercado de órganos, pues sus habitantes se abandonan al placer virtual y por consiguiente se convierten en víctimas incautas de quienes les amputan sus extremidades de manera artera. Mientras los mexicanos “de bien” duermen el sueño de los injustos, otros aprovechan para cercenarles partes de su anatomía y cauterizar sus heridas, evitando dejar rastros reveladores. Lo auténticamente traumático de este desenlace es que la amputación no es fruto de un ajuste de cuentas, como parece en primera instancia -en busca de justicia social, dirían algunos extremistas-, sino que responde a una dinámica más vil, de simple y pura oferta y demanda: les cortan las extremidades sencillamente porque hay quienes están dispuestos a pagar toneladas de dinero por ellas. En síntesis, pareciera que lo que a Bef le interesara, mediante este juego escabroso de ilusiones y desmembramientos, fuera proponer un exacerbamiento del capitalismo como modalidad preferencial de la futura nación azteca.

Sin embargo, el afianzamiento de la influencia nipona -y de Oriente en generalen el accionar identitario mexicano nos conduce en otra dirección. El México de Gel azul es un lugar en el que la influencia estadounidense se ha visto atenuada, y hasta rebasada, por el ritmo avasallador de la tecnología oriental. Si bien, de manera irónica y al cabo de los años, México se ha convertido en un país de inmigrantes, a la manera de los Estados Unidos, con negros argelinos haciendo las veces de taxistas, balbuceando mezclas de francés, árabe y español, y ofreciendo anfetaminas y ácido a sus pasajeros, y mercaderes japoneses en las trastiendas de la calle de Bolívar, los restantes aspectos

\footnotetext{
Revista Iberoamericana, Vol. LXXVIII, Núms. 238-239, Enero-Junio 2012, 179-192 ISSN 0034-9631 (Impreso) 
de la evolución social y cultural de la unión americana se destacan por su ausencia. A primera vista, los norteamericanos, tan tangibles en el México presente, no aparecen por ninguna parte en la trama. El único personaje con nombre de anglosajón es la Bestia McGregor, el asesino a sueldo encargado de eliminar a Crajales al final de la historia. Y McGregor no sobresale necesariamente por su intelecto; por algo lleva a cuestas el remoquete de “Bestia”. Su gran virtud es la fuerza bruta. Cuando le es encomendada la tarea de eliminar al detective, descubre a la esposa del mismo en flagrante adulterio y, confundiendo a su víctima, despacha al amante (el licenciado Quiñones, desafortunado jefe de la muchacha) (117). De manera un tanto tangencial, el único otro rastro de influencia anglosajona se da-como habría de esperarse-en elámbito de una heterogénea oferta virtual religiosa, con cultos como la Iglesia del Cristo Extraterrestre, el Cristorrecepcionismo, los Kennedytas, San Elvis y las Hijas de la Virgen Ahogada (38).

Las referencias a Japón, en cambio, se dan de manera reiterada y complejizan lo identitario en un mayor grado. Es japonés Kimura-San, quien, desde la calle de Bolívar, en la tradicional zona de casas de música del Centro Histórico, hace las veces de contacto para Crajales y lo previene del carácter riesgoso de su empresa a inquirir acerca del tenebroso mundo del tráfico de órganos. También son japonesas las máquinas empleadas para sumirse en el sueño virtual. Desarrollados por HumaCorp, con sede en el distrito de Shibuya, en Tokio, y ensamblados en Brasil, los Gokubi, los tanques llenos de materia proteínica en los que las personas adineradas anhelan sumergirse, representan el colmo de la exclusividad en una sociedad obsesionada con explorar alternativas sensoriales. ${ }^{1}$ De hecho, es con personal de la HumaCorp -y de la empresa coreana de seguridad digital KooSong, pues éstos también hacen de las suyas- con quien tendrá que lidiar Gloria Cubil al enfrentarse a las exasperantes limitaciones de la Red, a su juicio: un soporte místico insuficiente, la incapacidad de revelar sus sueños, etc. La mención de Shibuya, en particular, es bastante esclarecedora del tipo de influencia imperante. Al fin y al cabo, el distrito comercial tokiota, con sus enormes pantallas digitales, grandes luces de neón y multitudes de gente, funge de arquetipo para la urbe scottiana de Blade Runner y es casi de mención obligatoria en muchos relatos de este corte. Dentro de este marco, Oriente, con su encumbrada implementación tecnológica y controvertiblenivel de vida, tiene mucho de distopía. ¿Qué mejor modelo de distopía que el Japón finisecular?, con tecnología ubicua, hacinamiento en abundancia y una cultura opresiva y sofocante, cercenante de toda individualidad. Lo de Brasil, en cambio, pese a una primera impresión, ni siquiera apunta en otra dirección. Después de todo, la nación sudamericana es sede de la mayor colonia de emigrantes japoneses en el mundo, plena de nisei (descendientes de segunda generación) y sansei (de tercera generación). Y en cuanto a los coreanos, su emulación y exacerbación de lo japonés, dada su perturbadora experiencia colonial,

1 El nombre proviene de una empresa japonesa real, dedicada al negocio de la bioindustria.

Revista Iberoamericana, Vol. LXXVIII, Núms. 238-239, Enero-Junio 2012, $179-192$
ISSN 0034-9631 (Impreso) 
es de amplio conocimiento. Aparte de eso, el hecho de que Crajales se demore cuatro horas en llegar del trabajo a casa, cual agotado sarariman tokiota -con una forma de vida centrada en el trabajo, enteramente carente de iniciativa y singularidad-, dista de ser casual. Con una oficina diminuta y un apartamento de dos ambientes (de dieciséis metros cuadrados cada uno), en el que la pareja tiene que conformarse con una repisa a la hora de hacer el amor, la vida de Crajales tiene mucho de urbe nipona y poco de la dilatación y el confort de una tradicional megalópolis americana. De cualquier manera, lo que se evidencia es que el paradigma a relucir, en cuanto a esparcimiento y pujanza económica se trata, no se remonta al orden del norte del río Bravo, sino a cuanto sucede al otro lado del Pacífico. De esta manera, Bef plasma un México que, pese a no haber logrado grandes aciertos en materia de equidad social, se acomoda de manera un tanto fastidiosa hacia poniente. En síntesis, el proyecto de nación azteca madura cual ínsula de Oriente.

También, a la manera de los japoneses, éste es un México introspectivo, el cual ha asumido una mentalidad interiorizadora de experiencias. Si bien la tecnología le ha permitido una comunicación más eficiente -y conviene recordar que buena parte de la fortuna del archibillonario Carlos Slim Helú proviene del sector de las telecomunicaciones- al mismo tiempo ha agravado la sensación de aislamiento acompañante de la modernidad. El México de Gel azul es, pese a la inmigración (el otro en casa) y los avances comunicativos (un mar de alteridades virtuales), un país muy metido en sí mismo y aún menos conocedor de su propia condición, dada la capacidad de refugio de algunos habitantes y el extravío de otros. Como buen relato de ciberpunk, Gel no rebasa pequeñas fronteras: para eso está el espacio virtual, ilimitado. Es por ello que, en su narrativa, lo nacional adquiere una calidad casi autista, si bien algo consciente de cuanto acontece afuera, muy encerrado en su interior, como un cuerpo suspendido en un tubo de plexiglás repleto de líquido. Y este esquema, se me hace a mí, se asemeja en sí a una apropiación de la disposición nipona, muy independiente del ilusorio brochazo de modernidad. En otras palabras: lo de la era Meiji (1867-1912), el proceso económico y cultural mediante el cual, en un lapso de cuarentaicinco años, Japón pasó de un feudalismo decimonónico, encarnado en el shogunato Tokugawa, a un capitalismo industrial con matices de potencia mundial, fue puro simulacro. En México, por el contrario, lo del TLC ni siquiera ha llegado a eso.

De esta manera, acogiéndose a las convenciones del ciberpunk, el trauma cultural nipón sirve de modelo a la crisis identitaria azteca. Durante la era Meiji una de las mayores motivaciones para modernizar la sociedad fue el latente miedo a una invasión occidental, de manera que la xenofobia, aunada a un creciente sentimiento nacionalista y la homogeneidad cultural, sirvió de mecanismo activador principal a la consolidación de la nación. En términos nominales, el arribo del comodoro Matthew Perry en 1853 puede que haya acabado con la política de sakoku (país encadenado o asegurado), según

\footnotetext{
Revista Iberoamericana, Vol. LXXVIII, Núms. 238-239, Enero-Junio 2012, 179-192 ISSN 0034-9631 (Impreso) ISSN 2154-4794 (Electrónico)
} 
la cual un ciudadano podía ser castigado por abandonar las fronteras nacionales, pero la occidentalización del Japón fue, por la mayor parte, quizás por el mismo afán local en las apariencias, un asunto de formas. En México, en comparación, la modernización, pese a también afianzarse en la fijación colectiva de una norteamericanización acelerada por el libre comercio -el miedo a la invasión-, se ha dado de manera disonante, tanto en lo económico como en lo cultural. El modelo japonés, según el cual había que implementar una modernización occidental con códigos autóctonos, no ha sido viable. En un abrir y cerrar de ojos la nación azteca se ha llenado de celulares, redes inalámbricas y computadoras por doquier, mas la inequidad social ha aumentado de forma preocupante. Y poco debajo de la superficie, más allá del exiguo encandilamiento de la modernidad, se atisba un México profundo, atávico e idiosincrásico, al igual que el Japón contemporáneo. Bernardo Fernández no es el primero entre la presente generación de actores culturales aztecas en lidiar con este tipo de lectura. Ya bien lo ha hecho antes el director de cine Carlos Reygadas, aunque desde otra coordenada. En Japón, su afamada cinta de 2002, postula un acercamiento al estilo y la temática del cine nipón partiendo de un adentramiento en un México profundo. Fernández, a cambio, lo hace de manera más artificiosa: simulando un ensanchamiento tecnológico que, en últimas, patentiza una mayor abstracción. En este sentido, el mundo de Gel se asemeja mucho más al Japón del presente, con tecnología a tutiplén, vida desquiciante y una eterna recesión, y, de paso, al México del futuro que muchos se aventuran a pronosticar.

Aparte de eso, conviene por supuesto destacar que lo japonés es, de hecho, una característica propia del género, según lo señala William Gibson en su artículo “Japan As the World Sees It”. Para Gibson, padre incontrovertible del ciberpunk, la forma apresurada y esquizofrénica como Japón digirió las lecciones de la era victoriana -en particular, una asimilación acrítica de los procesos originadores de la Revolución Industrial- explican la dislocación y el trauma cultural de la población nipona, por un lado tan afanada en lograr el progreso económico, pero por otro tan renuente a abandonar su orden ancestral, fundamentado en ritos y jerarquías -conflicto plasmado de manera diáfana en Botchan (1906), el relato cardinal de aprendizaje del insigne Natsume Soseki-. En el caso de México, dado el proceso de libre comercio, incentivador de algunos sectores de la economía y verdugo de otros, y la vigorización de distritos comerciales como Santa Fe y Puerta de Hierro, en el DF y Guadalajara, de manera respectiva, las lecciones de una modernidad apresurada y carente de vínculos fehacientes con un principio orgánico saltan a la vista. Por ende, la presencia de lo nipón es materia imprescindible en un relato como Gel azul, interesado en formular una aproximación crítica a la realidad nacional mediante un coqueteo con el futuro. Sin embargo, si Japón figura de manera preponderante en $\mathrm{Gel}$, esto es, no sólo porque las convenciones del género así lo exigen, sino también porque el momento cultural y económico por el que atraviesa el país azteca, de cierta manera, guarda mucho en común con la coyuntura nipona de un siglo atrás.

Revista Iberoamericana, Vol. LXXVIII, Núms. 238-239, Enero-Junio 2012, $179-192$
ISSN 0034-9631 (Impreso) 
En cuanto al ensimismamiento azteca, Fernández reproduce esta sensación de diferentes maneras. Hacia el comienzo de la historia, cuando hace un flashback para explicarnos el pasado de Crajales, evoca el eslogan de Alien (1979), otra obra superlativa de Ridley Scott: "en el ciberespacio no había sonidos” (41). In space no one can hear you scream (en el espacio, nadie puede escuchar tus gritos), reza el lema de la cinta. Imaginarse la experiencia virtual -así sea por el breve lapso de unas cuantas páginas, cuando se describen los avatares de un adolescente de catorce años- como un mundo mudo nos invita a contemplar la ficción como una experiencia intimista, casi enajenante. En ese instante, el mundo virtual es materia de imágenes sin sonido, muy próximo a nuestras divagaciones. Infortunadamente, este mundo afónico, como bien sabemos, en el que un Crajales de catorce años logra burlar a un banco, no durará demasiado. Por un lado, las interfases multisensoriales serán inventadas muy pronto, apunta la narrativa. Y por otro, porque esta experiencia apenas antecede el descalabro del protagonista con el percance de la tarjeta de crédito. De igual manera, al imaginarnos los viajes de Gloria Cubil con sonido y en tecnicólor, cual una serie de cortometrajes que ocupan buena parte de la narrativa (amén de la vocación óptica de la prosa de Fernández), no dejamos de recordar su cuerpo suspendido en una sustancia coloidal, en un ambiente pleno de resonancias. La aparente realidad, tan vistosa y asequible, esconde una meditación interior. Tal vez Gloria disfrute de sus devaneos por universos virtuales, pero, según el texto, siempre está consciente de su mundo interior, el cual, en última instancia, prima. A partir de estos mecanismos, pautadores del ritmo de la trama, Fernández nos recuerda constantemente la vocación intimista de su formulación identitaria, cimentada en construcciones ajenas.

Este interés por examinar versiones de la mexicanidad amparadas por vivencias ajenas no es nuevo en el marco de las letras mexicanas. De hecho, un buen porcentaje de la producción de autores finiseculares -los del crack, por ejemplo: Volpi, Padilla, etc.- se preocupa por delinear un accionar identitario más cosmopolita, más ocupado en definir la mexicanidad a partir de cuanto sucede más allá de una frontera nacional. En el caso de Bernardo Fernández, sin embargo, la novedad radica en apropiarse del marco interpretativo de la ciencia-ficción en el que las circunstancias futuras conceden mayor autonomía a la hora de contemplar diferencias identitarias. Por ello, aparecen espacios habituales de la burguesía mexicana, como Polanco, al igual que imágenes recurrentes de la realidad nacional, como un campamento de purépechas sobre el Eje Central, con consignas que impugnan: "Fuera travajadores rrobots [sic] de la pisca de la fresa" y "Governador acecino [sic]” (48). Sin embargo, Polanco sólo se nombra para situar el apartamento de Gloria, en donde está instalado el tanque de gel azul con el cuerpo de la víctima y, a diferencia de la actualidad, cuando tienen que vérselas con el gobierno, los indígenas no protestan por agresiones entre humanos, sino por la intromisión de humanoides en época de cosecha.

\footnotetext{
Revista Iberoamericana, Vol. LXXVIII, Núms. 238-239, Enero-Junio 2012, 179-192 ISSN 0034-9631 (Impreso) 
No obstante, es en los Gokubi, los tanques repletos de gel azul con acceso a mundos virtuales, donde se encuentra una clave. Gokubi es también el nombre del traductor simultáneo inventado por el científico japonés Zenji Hiroguchi, personaje de Galápagos (1985), la estupenda novela del autor norteamericano Kurt Vonnegut (1922-2007). Cabe anotar que Bernardo Fernández es un vonnegutista declarado y que la inclusión de dicho nombre no es la única de las piezas sueltas por dondequiera, pues, según acostumbran hacer muchos escritores, a Bef le encanta dejar guiños a diestra y siniestra. ${ }^{2}$ El empleo de esta palabra es apenas uno de ellos. Cabría también entonces preguntarse, ¿no mencioné que había escasa presencia estadounidense en la obra? A este respecto, sólo resta responder lo siguiente: la novela puede que evoque la literatura anglosajona (el presente o el pasado cercano), mas el contenido de la misma, al igual que la de Vonnegut, se afianza en la creciente influencia de una técnica oriental y es a partir de ella que se construye una posibilidad de futuro. En otras palabras, la problematización del futuro de un proyecto de nación conlleva la exploración de un esquema japonés en ambas obras, Gel y Galápagos. Fernández se remite al autor estadounidense en la medida en que éste se remite a Japón como modelo de distopía. En el contexto de la obra de Vonnegut, el Gokubi es "una computadora de bolsillo capaz de traducir muchos lenguajes de modo instantáneo” (20). En Galápagos, Vonnegut plantea una crítica mordaz de la humanidad, sugiriendo el carácter dañino de toda tecnología y coqueteando con la probabilidad de involución como camino de supervivencia. Abandonados en la isla de Santa Rosalía, luego de una catastrófica epidemia que imposibilita la reproducción de la restante humanidad, los personajes de Galápagos mutan a lo largo de millones de años, transformándose en mamíferos acuáticos. (En la novela de Vonnegut, la primera en dar a luz un bebé con indicios de involución es descendiente de una sobreviviente de Hiroshima.) Por tanto, mayor injerencia de Galápagos se evidencia en los apartes intermitentes de un sueño virtual en el libro, en los que una criatura semejante a una orca, un cetáceo de color negro -¿acaso Crajales?, en un principio no queda claro- surca las aguas de manera azarosa $(47,67,88,130)$, en un eco de los descendientes de los habitantes de Santa Rosalía. Después de todo, cuando Salgado describe sus experiencias virtuales ante Crajales, le informa acerca de su adopción de la apariencia de una mantarraya y, al iniciarse el relato, según se ha mencionado antes, Gloria toma forma de medusa. En suma, los personajes de Gel terminan, así sea de manera virtual, de la misma manera que los protagonistas de Galápagos: internándose en el mar (un medio líquido ideal para la suspensión) a punta de involución. Al parecer, la relación con un medio fluido remite a una experiencia sensorial más auténtica, de índole embrionaria. Partiendo de esta coincidencia, teniendo en mente la argumentación narrativa de Galápagos, lo que

2 Este efecto es notable en el perfil de Fernández en su página de Facebook. Mis conclusiones también parten de un breve intercambio electrónico con el escritor.

Revista Iberoamericana, Vol. LXXVIII, Núms. 238-239, Enero-Junio 2012, $179-192$
ISSN 0034-9631 (Impreso) 
salta a la vista es la crítica de la tecnología, que, en última instancia, es la que viabiliza una transformación involutiva. Así como Vonnegut rechaza la adopción acrítica de la tecnología, Fernández parece sugerir que el esconderse en los recovecos del mundo virtual no puede conducir a nada bueno.

En el caso de Galápagos, la moraleja es que el mayor estorbo para la supervivencia de la humanidad es el tamaño de nuestros cerebros, de ahí que se plantee, mediante una respuesta prolongada de la naturaleza, en alusión concreta a Darwin, la posibilidad de una involución. Por tanto, resulta muy revelador que el autor de Gel azul haya optado por bautizar sus máquinas de experiencia virtual con el mismo nombre, sugiriendo la naturaleza dañina de ámbitos sustentados de manera casi exclusiva por el dominio de lo cerebral. Confiar en exceso en lo experimentado mediante una práctica neural parece albergar riesgos impredecibles: que le corten a uno las extremidades, como al periodista Salgado, o hasta una violación, conduciendo a un embarazo, como en el caso de Gloria Cubil. En este sentido, Fernández le hace el juego a Vonnegut. El abandonarse al placer de la sinapsis no sugiere, dentro del contexto de ambas obras, nada bueno. Y dentro de esta tónica, haciéndole el juego a una lectura macabra, que le corten a uno los miembros puede concebirse como una suerte de involución forzosa, un tanto apresurada. Según esto, el cerebro y sus engendros, fundados en el intelecto humano, agenciando conocimiento empírico promotor de avances tecnológicos, son una puerta falsa a la equidad social. Glorificar la ciencia, adoptarla sin una disposición crítica, puede resultar nefasto.

A México, parece ratificar Bef, no le conviene adentrarse en experiencias virtuales por el solo hecho de plantear una novedad literaria -acaso lo del libre comercio sea eso, el reflejo virtual de una modernidad-, pues sólo arrastrarán consigo calamidades y la negación general de diferencias. Si ha de hacerse uso del mundo virtual para efectos de una trama, lo clave es que dicho ejercicio sirva como mecanismo de exploración de la condición mexicana. Para ser concretos, la trama plantea un aparente sinsentido, pues Crajales es contratado por los responsables mismos de la violación de Gloria Cubil y del posterior fallecimiento de su recién nacido, con el fin de enviarle una advertencia a su padre, el ricachón Cubil, con respecto a rivalidades en el mercado de tráfico de órganos. En términos de la intriga, apenas descifrable hacia el final de la trama, la pulsión fundamental de la historia es la rivalidad entre el abogado Iñaki Beltrán, de la prestigiosa firma de abogados Montero, Escuer y Salinas Suárez del Real (según las iniciales, messr, los señores del juego), y su jefe Cubil por hacerse a un mercado suplantador de los vicios previos. Lo triste radica en que, en el contexto de la obra, este tráfico sea el producto de guerras iniciadas por la humanidad con el objeto de reactivar la economía mundial, la cual se hundió en un estado de postración tras la legalización de las drogas en los EE.UU. De manera casi inesperada, México logró superar esta coyuntura a punta de usos inventivos de la marihuana (papel, textiles), el petróleo y el turismo. Empero, no deja de ser paradójico que una medida ambicionada por muchas

\footnotetext{
Revista Iberoamericana, Vol. LXXVIII, Núms. 238-239, Enero-Junio 2012, 179-192 
naciones latinoamericanas, tras años de estar batallando un conflicto pírrico en contra de las consecuencias del voraz apetito de estupefacientes, termine siendo el mecanismo accionador del colapso de muchas economías.

De igual forma, el hecho de que la mayoría de los protagonistas no tengan que ver en realidad con lo que acontece tras las bambalinas -Crajales es tan sólo un señuelo, un chivo expiatorio, y Gloria poco sabe de los enredos en los que está metido su padre-nos deja una sensación de inutilidad, pues el desenlace poco depende de ellos. Fernández tiene muchas formas de hacernos entender esto, una crítica velada al México del presente, en el que la suerte de millones no se define a partir de circunstancias propias. Cuando Crajales visita a Kimura-San, alcanza a distinguir en el fondo del recinto un rompecabezas con una reproducción de El pez grande se come al chico, la consabida obra de Brueghel. Para Crajales, el rompecabezas no deja de ser un pasatiempo, pese a darse cuenta, a la hora de armarlo, que le falta una pieza. Para el lector, en cambio, la mención del grabado, tan alusivo a cómo los poderosos se ceban a punta de débiles, no puede pasar desapercibida como reafirmación del carácter general de la novela. Sin lugar a duda, una vez contemplada la mención de la imagen, como buena novela de ciencia-ficción, éste es un relato desesperanzador en el que los chicos aparentan tener cierta capacidad de respuesta, mas la cual, en última instancia, cuenta bien poco.

Por otro lado, tiene que tomarse en cuenta la estructura binaria del relato. Los viajes de Gloria forman una línea narrativa a lo largo de la novela que contrasta de manera pronunciada con los episodios dedicados a Crajales. Siendo hija del hombre más rico del país, Gloria bien pudiera hacerse a cuanto artículo le viniera en gana, pero el enorme vacío en su vida -proveniente, sin lugar a duda, del hecho de no faltarle nada y poder conseguirlo todo- le incita a aventurarse y buscar experiencias más recónditas, más introspectivas. En ocasión anterior, ya ha pasado por una clínica de rehabilitación y sus delirios por los mundos virtuales, a veces teñidos de misantropía, no son sino el fruto del desespero por encontrarle un sentido a sus vivencias. Pobre niña rica. Gloria representa, hasta cierto punto, el típico miembro de la élite latinoamericana. Cuando cree haber llegado a la meta de sus sueños en un rincón virtual de un bazar árabe ni siquiera se percata de que ha sido engañada por un programa diseñado para emular las apetencias más íntimas de sus ocupantes (76). Y cuando por fin llega a un lugar capaz de proporcionarle cierto sosiego, con el fin de combatir su depresión, su catarsis se limita a admitir haber soñado dar a luz, sin entender que su estado no es ficticio, sino más bien el producto real de un trance hormonal.

Lo de Crajales, en cambio, es un mundo feroz, inhóspito. El contraste es explícito. Gloria es bellísima; Crajales es feo a más no poder. Ella encarna la utopía sensorial. Él, al igual que muchos de sus compatriotas, padece el mundo real: las cuatro horas de metro, los mendigos por todas partes y el acoso de los delincuentes adolescentes. A Crajales le toca lidiar con el trajín de una ciudad implacable, envejecedora. Y para

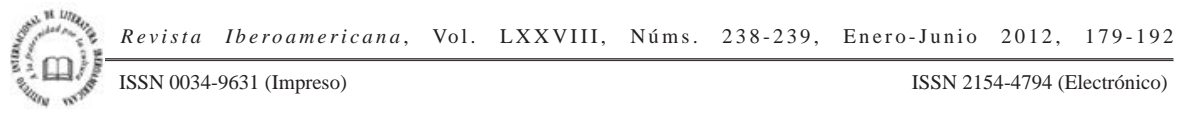


colmo, para ganarse la vida le toca pasearse por los rincones más oscuros y sórdidos e indagar acerca de las facetas más deleznables de sus clientes. La gran contradicción se manifiesta en que cada uno quiere lo que el otro tiene: como toda niña malcriada, insatisfecha con cuanto regalo le ha dado su padre, Gloria anhela el amor verdadero, imaginando una forma pura de contacto con la realidad, mientras que Crajales, hastiado de cuanta basura le rodea, ansía sumergirse en un tanque de plexiglás y dejarse llevar por un sueño reparador. Gloria aspira a un ideal; Crajales sólo experimenta el horror de la realidad, cual personaje de Conrad.

De esta manera, los protagonistas de Gel azul emulan las tensiones básicas de polos opuestos de la sociedad azteca, ignorando los mundanos intereses de la clase media: una mejor casa, un coche confiable, buena educación para los hijos, comida sobre la mesa, etc. Sólo los extremos valen en un futuro en el que México, en vez de haber nivelado su sociedad hacia el centro, ha degenerado en vértices. Es a partir de la exploración de los desmanes de estos cabos que se invita a los lectores a adoptar posturas más sensatas, menos fincadas en las veleidades del mercado cultural o en iniciativas de corte populista, diseñadas para manipular a la población. Habiendo aprehendido los excesos de las pasadas elecciones de 2006 en los que la nación mexicana se vio inmersa en una suerte de remedo tardío de la contienda presidencial norteamericana del año 2000, con una población polarizada a partir de discursos diametralmente opuestos, no extraña que Fernández, a la hora de plantear una historia de ciencia-ficción, opte por una mecánica binaria.

Ahora bien, el azul del título no es coincidencia. Desde la trillada frase de Rimbaud a manera de epígrafe -Hay que ser absolutamente modernos- hasta la vistosidad del lenguaje, que cabalga entre un registro mexicano bastante neutro y modismos de fuerte arraigo popular, nos obliga a repensar la función de las letras aztecas en un siglo en el que la tecnología está modificando nuestra forma de leer. A Fernández le da por combinar la exploración de escapismos futuristas con visos de novela negra, engendrando, acaso destilando, un ejemplar notable del cyberpunk latinoamericano. Por algo atestigua el lema de su página de Facebook: "Soy un punk de la secreta”. El punk busca, ante todo, violentar las normas sociales, ofendiendo la moral burguesa, el llamado "buen gusto" y la tradición. El ciberpunk lo logra valiéndose de tecnología. En el caso de Bef, lo clave es hacer esto de manera incógnita. El afán no es mecer los cimientos, por lo menos no de manera frontal, incitando todo tipo de alarmas. El afán es hacer un aporte al entendimiento del momento por el que pasa la sociedad mexicana, con una modernidad bastante desigual, mediante el lenguaje y la problematización de coyunturas futuras. En otras palabras, si los modernistas estuvieran vivos hoy, de seguro estarían escribiendo cosas de este tipo.

\footnotetext{
Revista Iberoamericana, Vol. LXXVIII, Núms. 238-239, Enero-Junio 2012, 179-192 ISSN 0034-9631 (Impreso) 
BiBLIOGRAFÍA

Alien. Dir. Ridley Scott. Twentieth Century-Fox, 1979.

Blade Runner. Dir. Ridley Scott. Warner Bros. Pictures, 1982.

Fernández, Bernardo. Gel azul. México: Suma de Letras, 2009.

“Bernardo Fernández Bef”. Facebook.com. 2011. <http://www.facebook.com/ profile.php?is=569190814\&sk=info>. 9 oct. 2011.

Gibson, William. “Japan As the World Sees It”. 30 de abril de 2001. TIME.com. < http:// www.time.com/time/asia/features/japan_view/scifi.html>. 6 dic. 2009.

Japón. Dir. Carlos Reygadas. Artecinema/Mantarraya Producciones, 2003.

Natsume, Soseki. Botchan. Tokio: Kodansha International, 2005.

Vonnegut, Kurt. Galápagos. Barcelona: Ediciones Minotauro, 1987.

$\begin{array}{llll}\text { ISSN 0034-9631 (Impreso) } & \text { ISSN 2154-4794 (Electrónico) }\end{array}$ 